\title{
Podoplanin (PDPN) affects the invasiveness of thyroid carcinoma cells by inducing ezrin, radixin and moesin (E/R/M) phosphorylation in association with matrix metalloproteinases
}

\author{
Justyna Sikorska ${ }^{\dagger}$, Damian Gaweł ${ }^{\dagger}$, Hanna Domek, Magdalena Rudzińska and Barbara Czarnocka* (D)
}

\begin{abstract}
Background: Podoplanin (PDPN) is a mucin-type transmembrane glycoprotein specific to the lymphatic system. PDPN expression has been found in various human tumors and is considered to be a marker of cancer. We had previously shown that PDPN expression contributes to carcinogenesis in the TPC1 papillary thyroid cancer-derived cell line by enhancing cell migration and invasiveness. The aim of this study was to determine the effect of PDPN down-regulation in another thyroid cancer-derived cell line: BCPAP.

Methods: In order to determine the effects of PDPN on malignant features of BCPAP cells (harboring the BRAFV600E mutated allele) and TPC1 cells (carrying the RET/PTC1 rearrangement), we silenced PDPN in these cells using small interfering RNA (siRNA). The efficacy of PDPN silencing was confirmed by qRT-PCR and Western blotting. Then, we tested the motility and invasiveness of these cells (using scratch test and Transwell assay), their growth capacities F(cell cycle analysis, viability, clonogenic activity) and apoptosis assays), adhesion-independent colony-formation capacities, as well as the effect of PDPN silencing on MMPs expression and activity (zymography).

Results: We found that PDPN-induced cell phenotype depended on the genetic background of thyroid tumor cells. PDPN down-regulation in BCPAP cells was negatively correlated with the migration and invasion, in contrast to TPC1 cells in which PDPN depletion resulted in enhanced migration and invasiveness. Moreover, our results suggest that in BCPAP cells, PDPN may be involved in the epithelial-mesenchymal transition (EMT) through regulating the expression of the ezrin, radixin and moesin (E/R/M) proteins, MMPs 9 and MMP2, remodeling of actin cytoskeleton and cellular protrusions. We also demonstrated that PDPN expression is associated with the MAPK signaling pathway. The inhibition of the MAPK pathway resulted in a decreased PDPN expression, increased E/R/M phosphorylation and reduced cell migration. Additionally, PDPN depleted BCPAP cells treated with inhibitors of MEK1/2 kinases (U0126) or of the BRAF V600E protein (PLX4720) had reduced motility, similar to that previously observed in TPC1 cells after PDPN knock-down.
\end{abstract}

Conclusions: Altogether, our data suggest that PDPN may play an important role in the control of invasion and migration of papillary thyroid carcinoma cells in association with the E/R/M, MMPs and MAPK kinases.

Keywords: Podoplanin, TPC1, BCPAP, Ezrin/radixin/moesin, Metalloproteinases, Motility, Invasiveness

\footnotetext{
* Correspondence: bczarnocka@cmkp.edu.pl

†Justyna Sikorska and Damian Gaweł contributed equally to this work.

Department of Biochemistry and Molecular Biology, Center of Postgraduate

Medical Education, Marymoncka 99/103, 01-813 Warsaw, Poland
}

(c) The Author(s). 2019 Open Access This article is distributed under the terms of the Creative Commons Attribution 4.0 International License (http://creativecommons.org/licenses/by/4.0/), which permits unrestricted use, distribution, and reproduction in any medium, provided you give appropriate credit to the original author(s) and the source, provide a link to the Creative Commons license, and indicate if changes were made. The Creative Commons Public Domain Dedication waiver (http://creativecommons.org/publicdomain/zero/1.0/) applies to the data made available in this article, unless otherwise stated. 


\section{Background}

Podoplanin (PDPN) is a $38-40 \mathrm{kDa}$ type I mucin-like transmembrane sialoglycoprotein which belongs to the podoplanin family [1-3]. It was initially identified in the kidney as a marker of podocytes [4] but it is also expressed in numerous other human tissues, such as skeletal muscles, heart, placenta, and lung [4-7]. PDPN is a useful marker of lymphatic endothelium and lymphangiogenesis as it is exclusively expressed in the lymphatic endothelial cells (LEC) but not in blood endothelial cells (BEC) [8]. PDPN is also upregulated in a variety of neoplasms, including colorectal tumors [9], squamous cell carcinomas $[5,6,10,11]$, mesothelioma [12], testicular seminoma [13], brain tumors [14-16] and some types of vascular tumors $[17,18]$ as well as in some papillary thyroid tumors [19]. Interestingly, in IHC analysis of the thyroid tissue specimens podoplnin was not detected in normal thyroid follicular cells or in non-tumorous cells of the peritumoral margin, but only in lymphoid endothelial cells of the lymphatic vessels [19].

PDPN function remains to be fully elucidated. Its role in the separation of the lymphatic and venous system during development by interacting with platelets was shown in several studies $[4,8,20]$. In tumors, PDPN may play an important role as a regulator of tumor cell migration and invasion, thus contributing to cancer progression and conferring poor prognosis [18, 21, 22]. Functional experiments performed in cell lines suggest that PDPN regulates the tumor cell motility. PDPN expression has been shown to promote cell scattering and the extracellular matrix (ECM) degradation in the $\mathrm{HaCaT}$ human immortalized keratinocyte cell line [5]. Additionally, it was shown that in-vitro PDPN-mediated invasion depends on the activity of matrix metalloproteinases (MMP) [11, 21] degrading ECM surrounding the tumor [23, 24]. In Madin-Darby Canine kidney cells (MDCK), PDPN has been shown to increase cell motility and induce the epithelial-mesenchymal transition (EMT) by switching the cells' migration pattern to a fast individualized cell locomotion and increased invasiveness [25]. Furthermore, high ectopic expression of PDPN has been shown to result in enhanced cancer cell migration, lymphangiogenesis and metastasis in the human MCF7 breast carcinoma xenograft model [26]. Moreover, in the same cell line model podoplanin was shown to be involved in collective migration of MCF 7 cells, without inducing EMT [11]. Moreover, Martín-Villar and collaborators showed that PDPN contributes to both directional migration of normal epithelial cells and cells derived from squamous cell carcinomas (SCC) [27].

Microscopy studies revealed that PDPN is concentrated in actin-rich plasma membrane protrusion structures, such as microvilli, ruffles, filopodia, and lamellipodia, where it colocalized with members of the E/R/M protein family.
Moreover, ectopic expression of PDPN in murine non-tumorigenic keratinocytic cells was shown to induce of actin cytoskeleton rearrangement and redistribution of ezrin to surface protrusions, as well as to enhance cell motility, suggesting PDPN contribution to the cell migratory potential [28]. Podoplanin could also be considered as an EMT inducer, as the malignant cells expressing PDPN often show a mesenchymal phenotype, that is characteristic feature EMT [29], and the presence of PDPN in lipid rafts is necessary for the recruitment and activation of $E / R / M$ proteins and induction of EMT as well as invadopodia functionality [29-31].

Previously we have demonstrated that PDPN mediates invasiveness in TPC1 cells derived from papillary thyroid carcinoma (PTC), that may suggest the involvement of PDPN in PTC progression. PDPN knock-down in TPC1 cells decreased cellular invasion and reduced cell migration. PDPN is up-regulated in both TPC1 and BcPAP papillary cancer-derived cell lines, however BcPAP cells, harboring the BRAF V600E mutation, have higher PDPN expression level. This may suggest that this gain-of-function mutation may be associated with a stronger induction of PDPN expression [19].

Therefore, we extended our analyses to the BcPAP cell line harboring a mutated BRAF allele (BRAF $V 600 E$ ), and expressing higher level of PDPN than TPC-1 cells. The BRAF V6OOE is a common mutation that plays a crucial role in tumorigenesis and progression of PTC [32-34]. Although signaling pathways activated by BRAFV600E and RET/PTC1 overlap, the tumors associated with each of these two alterations have unique phenotypic features, suggesting that they also may have different tumor biology [35-39].

Therefore, in the current study, we compared the function of PDPN expressed in PTC derived cell lines with different genetic background on the modulation of cell motility, migration and invasion associated with tumor progression. We demonstrate that PDPN knock-down either promote or suppress metastatic potential of thyroid cancer cell depending on the genetic background. Overall, our results suggest and support the role of PDPN in thyroid tumorigenesis.

\section{Methods}

\section{Cell lines and cell culture}

We used two thyroid cell lines derived from papillary thyroid carcinoma: BcPAP (German Collection of Microorganisms and Cell Cultures) which was previously tested and authenticated by DNA analysis, and TPC1 (established by Dr. Nobuo Sato) [40] and kindly provided by Dr. M. Santoro, The University of Naples Federico II, Italy). These cell lines differ in their genetic background: BcPAP cells carry the V600E mutation in the BRAF gene, while TPC1 cells harbor the RET/PTC1 
rearrangement. Both cell lines were cultured in RPMI-1640 medium (Lonza, Switzerland) supplemented with $10 \%$ fetal bovine serum (FBS; Thermo Fisher Scientific, USA), in humidified $5 \% \mathrm{CO} 2$ atmosphere at $37^{\circ} \mathrm{C}$. Viable cells were enumerated on the EVA Automatic Cell counter (Nano EnTek, Korea) following Trypane Blue staining. Both cell lines were tested for mycoplasma contamination on a regular basis.

\section{PDPN silencing with small interfering RNA (siRNA)}

BcPAP and TPC1 cells were transfected with siRNA targeting human PDPN (Thermo Fisher Scientific, Ambion, USA) and a universal negative control siRNA (MIS$\mathrm{SION}^{\circ}$ siRNA Universal Negative Control \#1, Sigma-Aldrich, USA) as described previously [19]. The efficiency of the PDPN knock-down was assessed by quantitative PCR of reverse-transcribed RNA (RT-qPCR), Western blotting and immunofluorescence (IF) $48 \mathrm{~h}$ after transfection. The experiment was repeated at least three times.

\section{RNA isolation and RT-qPCR}

Total RNA was isolated from thyroid cancer cell lines $48 \mathrm{~h}$ after transfection using the GeneMATRIX Universal RNA Purification Kit (EURx, Poland) in accordance with the manufacturer's instructions. Total RNA (500 ng) was reverse-transcribed using the Takara Reverse Transcription Kit (Takara, Japan). Then, qPCR reactions were performed as described previously [19], the mixture containing a Maxima SYBR Green/Fluorescein qPCR
Master Mix (Thermo Scientific, Canada) and specific oligonucleotide primers (Table 1).

Amplification, data acquisition and data analysis were carried out using the iQ5 Real-Time PCR Detection System and software (Bio-Rad, USA).

\section{Protein extraction, polyacrylamide gel electrophoresis (PAGE) and Western blotting}

For protein extraction, the cells were detached from culture vessels $48 \mathrm{~h}$ after transfection, and lysed as follows. The cell pellets were re-suspended in the RIPA lysis buffer $(150 \mathrm{mM}$ sodium chloride; $1.0 \% \mathrm{NP}-40$; $0.5 \%$ sodium deoxycholate; $0.1 \%$ SDS; $50 \mathrm{mM}$ Tris, $\mathrm{pH} 8.0$ ) supplemented with $1 \%$ protease and phosphatase inhibitor cocktail (Roche, Switzerland). Next, 30 $\mu \mathrm{g}$ of proteins were separated by electrophoresis in 10\% SDS-PAGE gels and then electro-transferred onto nitrocellulose membranes (Bio-Rad, USA). After blocking the non-specific sites with $5 \%$ BSA or $5 \%$ non-fat dry milk in TBS-T (Tris-buffered saline, pH 8.0-Tween 20 0,05\%), membranes were probed with primary antibodies (Table 2) by overnight incubation at $4{ }^{\circ} \mathrm{C}$, followed by incubation with the appropriate HRP-conjugated secondary antibodies (Jackson ImmunoResearch Laboratories, USA; Table 2). Finally, specific protein signals were detected using the SuperSignal West Pico Chemiluminescent Substrate or SuperSignal West Dura Extended Duration Substrate (ThermoFisher Scientific, USA) on ChemiDoc $\mathrm{XRS}^{+}$Imaging System (BioRad, USA) and quantified using the Quantity One software (BioRad, USA). As a loading control, the membranes were

Table 1 Sequences of used qPCR primers

\begin{tabular}{|c|c|c|}
\hline Gene name & Forward primer sequence & Reverse primer sequence \\
\hline PDPN & 5'-CGAAGATGATGTGGTGACTC-3' & 5'-CGATGCGAATGCCTGTTAC-3' \\
\hline EZR & 5'- TCTTCGCTGCTGCTGGATAG-3' & 5'-GGTGGTAACTCGGACATTGATTG-3' \\
\hline MSN & 5'-TGAGGCTGTGGAGTGGCAGC-3' & 5'-CTAGAGGCTGGGTGCCCATT-3' \\
\hline RDX & 5'-GGCAACACAAAGCTITTGCA-3' & 5'-ATATATGCAAAATAACAGCTC-3' \\
\hline MMP1 & 5'-CTGGCCACAACTGCCAAATG-3' & 5'-CTGTCCCTGAACAGCCCAGTACTTA-3' \\
\hline MMP2 & 5'-CAGGGAATGAGTACTGGGTCTATT-3' & 5'-ACTCCAGTTAAAGGCAGCATCTAC-3' \\
\hline MMP3 & 5'-GAAATGAGGTACGAGCTGGATACC-3' & 5'-ATGGCTGCATCGATTTTCCT-3' \\
\hline MMP7 & 5'-GCCTACCTATAACTGGAATG-3' & 5'-AGCCTTTGACACTAATCG-3' \\
\hline MMP9 & 5'-GCACGACGTCTTCCAGTACC-3' & 5'-CAGGATGTCATAGGTCACGTAGC-3' \\
\hline MMP13 & 5'-TCCCAGGAATTGGTGATAAAGTAGA-3' & 5'CTGGCATGACGCGAACAATA-3' \\
\hline SNAI1 & 5'-CCCAATCGGAAGCCTAACTA-3' & 5'-CAGGACAGAGTCCCAGATGAG-3' \\
\hline TWIST1 & 5'-CATCGACTTCCTCTACCAGGTC-3' & 5'-TCCATTTTCTCCTTCTCTGGAA-3' \\
\hline $\mathrm{RHOA}$ & 5'-TGCTTGCTCATAGTCTTCAG-3' & $5^{\prime}$-CACATCAGTATAACATCGGTATC-3' \\
\hline PTK2 & 5'-GGTGCAATGGAGCGAGTATT-3' & 5'-GCCAGTGAACCTCCTCTGA-3' \\
\hline PXN & 5'-ACGTCTACAGCTTCCCCAACAA-3' & 5'-AGCAGGCGGTCGAGTTCA-3' \\
\hline VIM & 5'-GACAATGCGTCTCTGGCACGTCTT-3' & 5-TCCTCCGCCTCCTGCAGGTTCTT-3' \\
\hline $18 \mathrm{~S}$ rRNA & 5'-CCAGTAAGTGCGGGGTCATAAG-3' & 5'-CCATCCAATCGGTAGTAGCG-3' \\
\hline
\end{tabular}


Table 2 Primary antibodies used by Western blotting and immunofluorescence studies

\begin{tabular}{lll}
\hline Targeted protein & $\begin{array}{l}\text { Other } \\
\text { characteristics }\end{array}$ & $\begin{array}{l}\text { Antibody name } \\
\text { (manufacturer) }\end{array}$ \\
\hline podoplanin & mouse mAb & $\begin{array}{l}\text { D2-40 (Biorad, AbD Serotec, } \\
\text { USA) }\end{array}$ \\
$\begin{array}{l}\text { phospho-ERM } \\
\text { phospho-p44/42 MAPK } \\
\text { (Erk1/2) }\end{array}$ & rabbit mAb & $\begin{array}{l}48 G 2 \text { (Cell Signaling, USA) } \\
\text { FAK }\end{array}$ \\
rabbit Ab & $\begin{array}{l}\text { Phospho FAK (Tyr397) } \\
\text { (Cell Signaling, USA) }\end{array}$ \\
paxillin & mouse mAb & 156-3C11 (Cell Signaling, USA) \\
vimentin & rabbit Ab & H-114 (Santa Cruz, USA) \\
snail & mouse mAb & Vim 3B4 (Abcam, UK) \\
twist & goat Ab & ab53519, (Abcam, UK) \\
RhoA & rabbit Ab & ab50581, (Abcam, UK) \\
\hline mAb: maling, USA)
\end{tabular}

re-probed with a monoclonal anti- $\beta$-actin antibody (Sigma-Aldrich, USA) following the same protocol.

\section{Immunofluorescent staining}

Forty-eight hours following transfection, cells were seeded on uncoated glass coverslips in 24-well plates at $1 \times 10^{5}$ cells $/ \mathrm{ml}$ and incubated for $72 \mathrm{~h}$. Then, they were fixed in 4\% PFA/PBS for $15 \mathrm{~min}$ and permeabilized in $0.25 \%$ Triton $^{\circ} \mathrm{X}-100$ for $10 \mathrm{~min}$. After blocking the non-specific sites in 2\% BSA/PBS-T (phosphate buffered saline, $\mathrm{pH} 7.3,0.05 \%$ Tween 20), cells were incubated with the following primary antibodies at $4{ }^{\circ} \mathrm{C}$ overnight: anti-phospho-ERM rabbit $\mathrm{mAb}$ (48G2, Cell Signaling, USA), anti-MMP2 mouse mAb (6E3F8, Abcam, UK), anti-MMP9 mouse mAb (5G3, Abcam, UK), and Phalloidin-FITC (Sigma-Aldrich, USA). Next, after several washes with PBST, the cells were incubated for one hour in the dark with the secondary antibodies: anti-mouse DyLight ${ }^{\text {tw }} 549$-conjugated, or goat anti-rabbit TRITC- or FITC-conjugated antibodies (Jackson ImmunoResearch Laboratories, USA). The cells were then counterstained with nuclear dye DAPI and visualized under a fluorescent and/or confocal microscope (AxioObserver D1 and AxioObserver Z1, Zeiss, Germany) using oil-immersion lenses. PDPN protein immunostaining was performed as described elsewhere [19].

\section{Cell migration and invasion assays}

Cell migration and invasion activity assays were performed as previously described [19] using Falcon ${ }^{\circ}$ Permeable Support for-24 Well Plate $(8.0 \mu \mathrm{m}$ pore size $)$ and Corning $^{\circ}$ BioCoat $^{\mathrm{Tm}}$ Matrigel $^{\ominus}$ Invasion Chambers $(8.0 \mu \mathrm{m})$ (Corning, USA). The cells that migrated were stained with a Diff-Quik Kit (Medion Diagnostics, Switzerland) and counted at a 40x magnification under the Olympus BX41 microscope. Each experiment was performed in triplicate and repeated three times.

\section{In vitro wound healing motility assay}

The cell motility assay was performed as described elsewhere [19]. The width of the wound was measured immediately after wounding (time $0 \mathrm{~h}$ ) and at 6-h intervals during $24 \mathrm{~h}$. Wound images were taken using a phase contrast microscope (AxioObserver D1, Zeiss, Germany) and measured in the ImageJ platform. The migration ability of the cells was then calculated by dividing the values by two and subtracting the results from the initial half-wound width as described by others [41].

\section{Colony formation assay}

After PDPN silencing or inhibitor treatment experiments, the TPC1 and BcPAP cells were counted using the EVE automatic cell counter (NanoEnTek, Korea). Then, 500 cells were seeded in one $100 \mathrm{~mm}$ Petri dish (three replicates for each experiment) and incubated in a $5 \% \mathrm{CO}_{2}$ humidified environment at $37^{\circ} \mathrm{C}$ for $7-12$ days, depending on the cell line. Next, the cells were fixed with $10 \%$ PFA for $25 \mathrm{~min}$, washed twice with water, and stained with crystal violet $(0.5 \% \mathrm{w} / \mathrm{v})$ for $15 \mathrm{~min}$. Digital images of the dried colonies were obtained using a scanning device and visible clones were counted using ImageJ.

\section{Anchorage-independent cell growth assay}

The soft agar colony formation assay was performed in 6-well culture plates. First, $3 \mathrm{ml}$ of $0.64 \%$ bottom agar (Roth, Germany) diluted in 10\% FBS-RPMI medium were added to each well and the plates were set aside for the agar to solidify. Meanwhile, the top agar layer was prepared by mixing the appropriate number of cells with the complete culture medium and $1.2 \%$ agar solution. The final mixture for one well contained $2 \mathrm{ml}$ of $0.3 \%$ agar-medium solution with $0.5 \times 10^{4} \mathrm{TPC} 1$ cells or $1 \times$ $10^{4}$ BcPAP cells. Next, the dishes containing two agar layers and cells were incubated at $37^{\circ} \mathrm{C}$ for two weeks. Fresh culture medium (10\% FBS-RPMI) was added after three days and then changed every three days. After two weeks, cell colonies were counted under a light microscope (AxioObserver D1, Zeiss, Germany) at a 10x and 40x magnification.

\section{Cell adhesion assay}

The assay was performed using the colorimetric ECM Cell Adhesion Array Kit (Merck Millipore, Germany) and also 96-well plates coated by ourselves. The ECM Array microtiter plates, pre-coated with different extracellular matrix proteins (Purified human Collagen I, 
Collagen II, Collagen IV, Fibronectin, Laminin, Tenascin, Vitronectin), were used according to the manufacturer's instructions. Independently, 96-well culture microplates (Corning, USA) were coated with fibronectin $(20 \mu \mathrm{g} / \mathrm{ml})$ or laminin-1 $(10 \mu \mathrm{g} / \mathrm{ml})$, and incubated at $4{ }^{\circ} \mathrm{C}$ overnight. Non-specific binding sites on the plates were blocked by a one-hour incubation with $0.5 \%$ BSA in the RPMI medium at $37^{\circ} \mathrm{C}$ in a $\mathrm{CO}_{2}$ incubator. Next, the cells were counted and re-suspended in the culture medium to final concentration. Then, $50 \mu$ l of cell suspension of $4 \times 10^{5}$ cells $/ \mathrm{ml}$ were seeded in the wells (in triplicates) and allowed to adhere for $30-60 \mathrm{~min}$ at $37^{\circ} \mathrm{C}$. After that, unattached cells were removed by washing, and adherent cells were fixed with 4\% PFA for 15 min and then stained with crystal violet solution (Sigma Aldrich, USA) for $10 \mathrm{~min}$. After extensive washing, the dye was extracted using $2 \%$ SDS and quantified by spectrophotometry at $550 \mathrm{~nm}$ using a microplate reader (Multiskan RC, Labsystems, Thermo, Finland).

\section{Cell viability assay}

The number of proliferating cells was determined by measuring the amount of 5-bromo-2'-doexyuridine (BrdU) incorporated into newly synthetized DNA using the BrdU Cell Proliferation Assay (Merck Millipore, USA). Forty eight hours after transfection with siRNA, the cells were seeded in 96 -well plates (5 replicates) and BrdU was added to each well. Next, the cells were incubated at $37^{\circ} \mathrm{C}$ for $17 \mathrm{~h}$ in a $5 \% \mathrm{CO}_{2}$ incubator and then treated following the manufacturer's instructions. Absorbance was measured at the test wavelength of $450 \mathrm{~nm}$ and the reference wavelength of $595 \mathrm{~nm}$ in the Labsystems Multiscan RC microplate reader (Thermo, Finland).

\section{Apoptosis assay}

Apoptosis was analyzed using the Annexin V-FITC Apoptosis Detection Kit (Abcam, UK) according to the manufacturer's protocol. Briefly, the cells were harvested, washed with PBS and incubated with FITC-Annexin V and propidium iodide for $5 \mathrm{~min}$ at room temperature. Afterwards, the labeled cells were analyzed by flow cytometry using BD FACSCanto ${ }^{\mathrm{TM}}$ II system (BD Biosciences, USA). The experiment was performed three times.

\section{Cell cycle analysis}

To distinguish cells in different phases of the cell cycle, propidium iodide (PI) staining was performed. The cells were harvested $48 \mathrm{~h}$ after transfection, washed with PBS and fixed with $70 \%$ ethanol at $-20^{\circ}$ $\mathrm{C}$ overnight. Then, the cells were washed twice, permeabilized with $0.1 \% \mathrm{NP}-40$ for $15 \mathrm{~min}$ and stained with $5 \mu \mathrm{g} / \mathrm{ml}$ PI solution (Sigma-Aldrich,
USA). Stained cells were analyzed by flow cytometry (FACSCantoII, BD Biosciences, USA). The experiment was repeated three times.

\section{Gelatin and collagen zymography}

For MMP activity measurement, cells $48 \mathrm{~h}$ after PDPN silencing the cells were washed with PBS and grown in serum-free medium at $37{ }^{\circ} \mathrm{C}$ in a humidified $5 \% \mathrm{CO}_{2}$ atmosphere. After $24 \mathrm{~h}$, the culture supernatant was collected and immediately stored at $-70{ }^{\circ} \mathrm{C}$ until further processing. Next, non-denatured conditioned medium samples were resolved using non-reducing SDS-PAGE, with gels containing $2 \mathrm{mg} / \mathrm{ml}$ gelatin or $0.5 \mathrm{mg} / \mathrm{ml}$ collagen type I (BD Biosciences, Bedford, MA, USA). Then, the gels were washed twice in $2.5 \%$ Triton $\mathrm{X}-100$ in $\mathrm{H}_{2} \mathrm{O}$ for $30 \mathrm{~min}$ and incubated in a developing buffer $(50 \mathrm{mM}$ Tris- $\mathrm{HCl}, \mathrm{pH} 7.5,10 \mathrm{mM} \mathrm{CaCl} 2,1 \mu \mathrm{M} \mathrm{ZnCl}$, $1 \%$ Triton $\mathrm{X}-100,0.02 \% \mathrm{NaN}_{3}$ ) for 3.5 days. Afterwards, they were staining with $0.5 \%$ Coomassie Brilliant Blue R250 in 30\% ethanol, $10 \%$ acetic acid for $30 \mathrm{~min}$, and then destained with $30 \%$ ethanol and 10\% acetic acid. Finally, gel images were captured on the ChemiDoc XRS+ Imaging System (BioRad, Hercules, CA, USA). The bands formed by MMP enzymatic activity were quantified using the Quantity One software (BioRad, Hercules, CA, USA).

\section{Inhibition of the MAPK signaling pathway}

To inhibit the MAPK signaling pathway in the studied cell lines we used two selective inhibitors: U0126 and PLX4720. U0126 (1,4-diamino-2,3-dicyano-1,4-bis[2-aminophenylthio] butadiene; Cell Signaling, USA) is a highly selective inhibitor of MEK 1 and MEK 2, and thus efficiently down-regulates the MAPK signaling pathway. PLX4720 (Abcam, UK), blocks the activation of the MAPK signaling by inhibiting ERK phosphorylation in cell lines carrying the BRAF V600E mutation but not in cells with wild-type BRAF. The BcPAP and TPC1 cells were treated with $50 \mathrm{uM}$ of U0126 or $10 \mathrm{uM}$ of PLX4720, both diluted in DMSO, for $24 \mathrm{~h}$. Cells treated with DMSO only were used as a negative control. The inhibition of MEK1/2 or ERK was confirmed by Western blotting.

\section{Data analysis}

Statistical data analyses and graphs were made with the Prism 6 software (GraphPad, USA). Statistical significance was determined using the nonparametric Mann-Whitney $U$ test and paired t-test, with the $P$ value below 0.05 being considered as indicative of a statistical significance. All results are presented as means with standard errors of the mean (SEMs) from at least three independent experiments. 


\section{Results}

Podoplanin silencing in papillary thyroid cancer cell lines In order to assess the role of PDPN in the biology of papillary thyroid cancer, we silenced the expression of PDPN in two papillary thyroid cancer cell lines: TPC1 and BcPAP by transfection with targeted siRNA (siPDPN). Negative control cells were transfected with negative siRNA (siNeg). RT-qPCR analyses demonstrated that siPDPN efficiently decreases PDPN levels $48 \mathrm{~h}$ after transfection in both thyroid cancer cell lines. We observed a four-fold reduction in the PDPN mRNA expression in BcPAP cell line (1.00 versus 0.25 in siNeg-transfected cells, $P<0.01$ ) and an over five-fold reduction in TPC1 cells $(1.00$ versus $0.19, P<0.01$; Fig. 1a). Although the cells retained low levels of PDPN mRNA which were detectable by qRT-PCR following transfection, PDPN protein levels were below the detection thresholds of Western blot and immunofluorescence analyses in both BcPAP and TPC1 cell lines (Fig. 1b-c).

The effect of podoplanin silencing on the motility, invasiveness, adhesion and proliferation of papillary thyroid cancer cells

Since the migration and invasion of cancer cells are crucial factors responsible for cancer progression, we first examined whether PDPN may impact the ability of cells to migrate. To this end, we performed classical wound healing assay and a chamber migration assay. Wound healing assays showed that TPC1 and BcPAP cells had different migration potentials: the PDPN-depleted BcPAP cells migrated faster than PDPN-depleted TPC1 cells (Fig. 2a). Similar results were obtained with the chamber migration test. The PDPN-depleted BcPAP cells migrated faster than siNeg-transfected control cells (98 and 36 cells/24h, respectively), whereas TPC1 cells transfected with siPDPN migrated slower than control TPC1 cells (36 versus 164 cells/24 h; Fig. 2b).

First, we tested the motility and migratory capacities of the cells by wound healing and chamber migration assays. We observed that in the BcPAP cell line the depletion of PDPN expression promotes cells migration, in contrast to the pro-metastatic role of PDPN in TPC1 cells. The effect of PDPN silencing on the motility of thyroid cancer cells (TPC1 and BcPAP) was investigated using a classical wound healing assay and a chamber migration assay. Wound healing assays showed that TPC1 and BcPAP cells had different migration potentials: the PDPN depleted BcPAP cells migrated faster than PDPN depleted TPC1 cells (Fig. 2a). Similar results were obtained by the chamber migration test. We found that BcPAP cells treated with siPDPN migrated faster than siNeg-transfected control cells (97.6 and 36 cells/24h, respectively), whereas TPC1 cells transfected with siPDPN migrated slower than control TPC1 cells (36 versus 164 cells/24 h; Fig. 2b).

Next, we analyzed the effect of reduced PDPN expression on the invasive potential of the cells by Matrigel

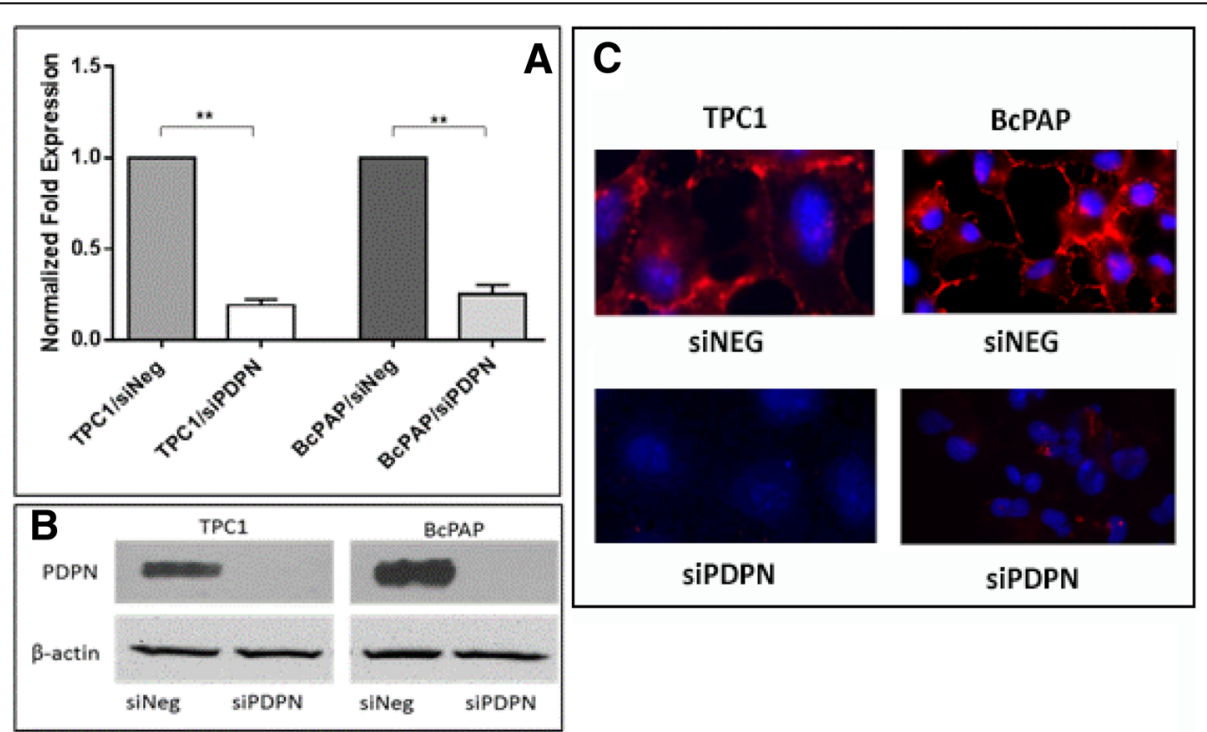

Fig. 1 Downregulation of podoplanin expression in BcPAP thyroid cancer cells following transfection with PDPN-specific siRNA. a. RT-qPCR analysis of PDPN mRNA levels in BCPAP cells $48 \mathrm{~h}$ after transfection with $30 \mathrm{nM}$ siRNA specific for PDPN (siPDPN) or negative control siRNA (siNeg). The results were normalized to the $18 \mathrm{~S}$ rRNA levels. The bars represent the average fold-change in PDPN transcript levels in cells transfected with siPDPN compared to control cells. The results are representative of four independent experiments. Data are presented as means \pm standard errors of the mean (SEM), **: $P<0.01$. b. Podoplanin protein levels in BCPAP cells $48 \mathrm{~h}$ after transfection with siPDPN or control siNeg by Western blot. $\beta$-actin was used as loading control c. Immunofluorescent staining of podoplanin in BCPAP cells transfected with siPDPN or control siNeg. Cells were stained with the anti-PDPN monoclonal antibody D2-40 followed by the DyLight549-conjugated secondary antibody (red), and counterstained with DAPI (blue). Magnification: 630x 


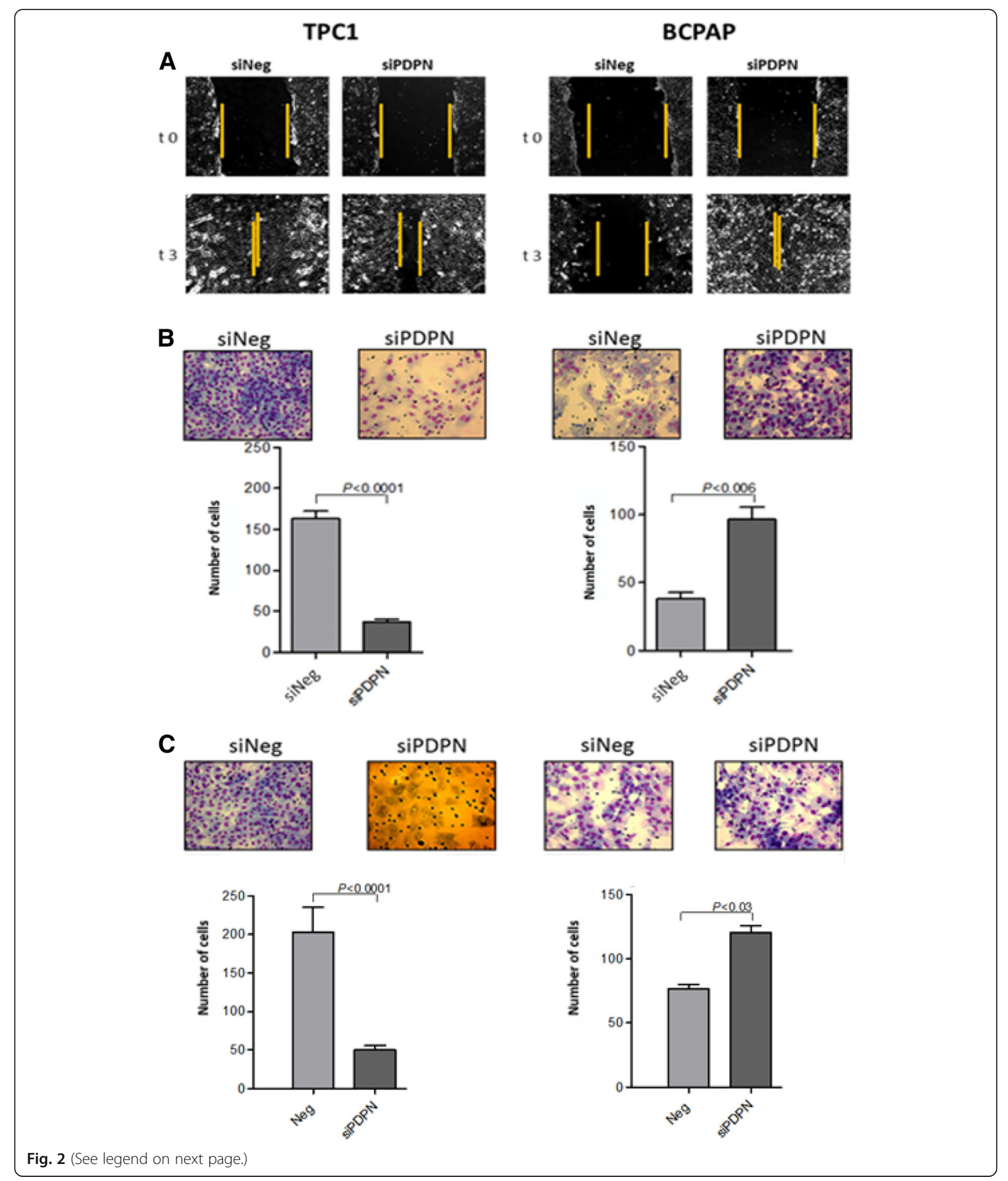


(See figure on previous page.)

Fig. 2 Podoplanin silencing reduces motility, migratory capacities and invasiveness of BCPAP and TPC1 cells. a. Wound healing motility assay. Representative light microscope images showing healing of wounds in monolayers of TPC1 and BCPAP cells transfected with siPDPN or control siNeg Magnification: 200x. b. Chamber migration assay. siPDPN or siNeg-transfected TPC1 and BCPAP cells were seeded in 8- $\mu$ m Boyden insert chambers, with the lower reservoir filled with medium supplemented with $10 \%$ FBS as a chemoattractant. After $24 \mathrm{~h}$, cells that had passed through the 8- $\mu \mathrm{m}$ membrane pores were fixed, stained with Diff-Quik and photographed at a 40x magnification.. Data are presented as means \pm standard errors of the mean (SEM) of at least three independet experiments. c. Matrigel invasion assay. siPDPN- or control siNeg-transfected TPC1 and BcPAP cells were seeded in 8- $\mu$ m Matrigel Invasion Chambers, with the lower reservoir filled with the culture medium supplemented with $10 \%$ FBS as a chemoattractant. After $24 \mathrm{~h}$, cells that had passed through the $8-\mu \mathrm{m}$ pores in the membrane were fixed with, stained with Diff-Quik Kit, and photographed at 40x magnification. The relative invasiveness of transfected cells is presented in graph form. Data are presented as the mean \pm SEM of at least three separate experiments

invasion assay. We found that invasiveness of PDPN depleted BcPAP cells was enhanced compared to control siNeg-transfected BcPAP cells (121.9 and 76.8 cells/24 h, respectively). This was in contrast to the TPC1 cell line in which the presence of PDPN promoted cell invasion (52 cells $/ 24 \mathrm{~h}$ for the PDPN depleted TPC1 cells versus 200 cells/24 h in siNeg-TPC1; Fig. 2c).

Furthermore, we analyzed whether PDPN silencing affects the colony formation and anchorage-independent growth of TPC1 and BcPAP cells. We found that reduced PDPN expression levels in BcPAP cell line increased its capacity to grow both on and independently of the substrate, in contrast to the phenotype observed for the PDPN depleted TPC1 cells (Fig. 3).

Finally we determined whether PDPN depletion influences the adhesion, viability/proliferation, cell cycle and apoptosis in BCPAP and TPC1 cells. We did not detect a consistent effect on cells adhesiveness, $\mathrm{G}_{1} / \mathrm{S}$ cell cycle arrest or viability (proliferation and apoptosis) of both studied thyroid cancer cell lines as shown by adhesion array as well as cell proliferation and viability assays (Additional file 1).
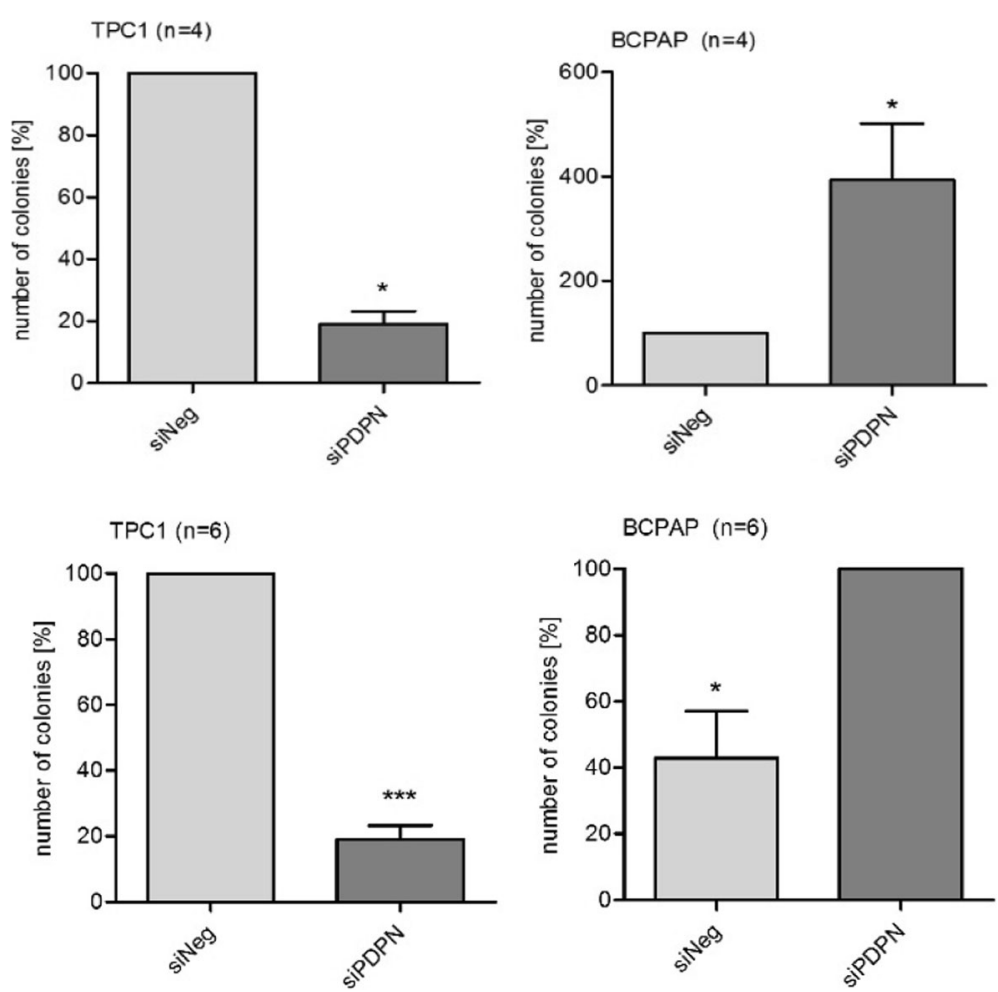

Fig. 3 Soft agar (upper panel) and colony formation assay (lower panel). To analyze colony formation and anchorage-independent growth of TPC1 and BCPAP cells after PDPN silencing, the cells were seeded into $100 \mathrm{~mm}$ Petri dishes or 6-well culture plates containing soft agar. Colonies were stained with crystal violet and counted under a white light microscope at a 10x and 40x magnification. Data are presented as means \pm standard errors of the mean (SEM) of results from at least three independent experiments, ${ }^{*}<P, 0.05, .{ }^{* *}<P, 0.001$ 


\section{Podoplanin knock-down enhances phosphorylation of E/ $\mathrm{R} / \mathrm{M}$ proteins}

ERM proteins act as crosslinkers between the cell membrane and actin cytoskeleton. They are also involved in regulating such cellular processes as reorganization of actin cytoskeleton, membrane dynamics, cell adhesion, and migration. Therefore, we analyzed the expression of E/R/M transcript and protein levels, and their phosphorylation status in BcPAP and TPC1 cells transfected with siPDPN and control siNeg RNA.
There were no statistically significant differences in the E/R/M mRNA expression levels between PDPN-deprived and control cells (Fig. 4a). However, Western blot analyses showed increased levels of phospho-E/R/M proteins in both TPC1 and BcPAP cells after PDPN silencing compared to control cells transfected with siNeg (Fig. 4b). Immunofluorescence co-staining of PDPN and phospho-E/R/M confirmed that PDPN depleted cells, both TPC1 and BcPAP, expressed higher levels of phospho-E/R/M than control cells (Fig. 4c). The results
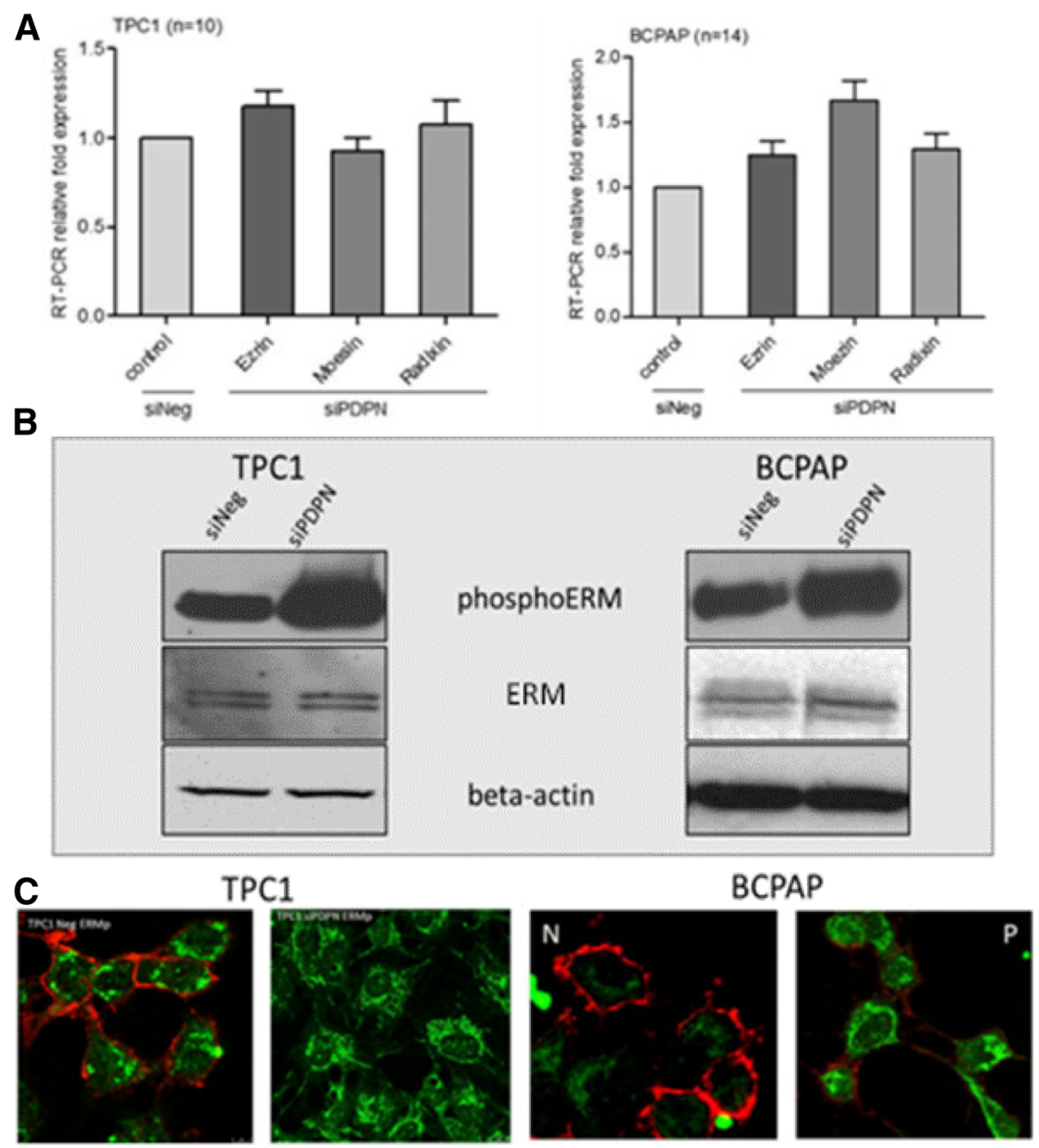

Fig. 4 Podoplanin silencing enhances phosphorylation of Ezrin, Radixin and Moesin (E/R/M) proteins in TPC1 and BcPAP thyroid cancer cells. a. RT-qPCR analysis of E/R/M mRNA levels $48 \mathrm{~h}$ after transfection with siPDPN or control siNeg. The results were normalized to the $18 \mathrm{~S}$ rRNA levels. The bars represent the average fold change in transcript levels in cells transfected with siPDPN compared to siNeg-transfected control cells. Data are presented as means \pm standard errors of the mean (SEM) of results from at least three independent experiments. $\mathbf{b}$. Western blot analysis of phospho-E/R/M protein levels $48 \mathrm{~h}$ after transfection. Total protein extracts were separated by SDS-PAGE, transferred onto a nitrocellulose membrane, and probed with specific antibodies. Beta-actin was used as a loading control. The results are representatives of three independent experiments. c. Immunofluorescent staining of podoplanin (red) and phospho-E/R/M (green) proteins in BCPAP (right panels) and TPC1 cells (left panels) transfected with siPDPN or control siNeg. Cells were co-stained with the anti-PDPN mouse antibody D2-40 and anti-phospho-E/R/M rabbit antibody followed by the DyLight549-conjugated anti-mouse secondary antibody (red) and FITC-conjugated anti-rabbit secondary antibody (green), and counterstained with DAPI (blue). Magnification: 630x 
indicate that a significant increase in the expression levels of phospho-E/R/M proteins is associated with the cellular expression of PDPN.

Furthermore, we analyzed the expression of $\mathrm{E} / \mathrm{R} / \mathrm{M}$ genes and proteins in response to PDPN silencing. We found that mRNA expression (Fig. 4a) and total E/R/M protein levels (Fig. 4b) did not change following siRNA transfection, whereas the levels of their phosphorylated forms increased.

\section{Cells phenotype and cytoskeleton organization changes}

As PDPN was shown to mediate remodeling of the actin cytoskeleton and induce cell migration, we analyzed filamentous actin distribution and cell morphology of papillary thyroid cancer cells $48 \mathrm{~h}$ after PDPN silencing. For cytoskeleton visualization, the cells transfected with siPDPN or siNeg were grown and fixed on glass coverslips and then stained with Phalloidin-FITC which selectively labels F-actin.

We observed that suppressing PDPN expression resulted in remodeling of cells' shape and cytoskeleton organization in both TPC1 and BcPAP cells. However, the two cell lines had markedly different morphologies following PDPN silencing. In TPC1 cells, PDPN depletion resulted in the impaired cell spreading with reduced protrusions, in BcPAP cells it induced an increase in the number of cellular protrusions (Fig. 5).

\section{Podoplanin regulates the E/R/M and EMT pathways in thyroid cancer cells}

In an attempt to elucidate the mechanism(s) through which PDPN affects the EMT pathway in papillary thyroid cancer, we studied the expression of several proteins involved in the E/R/M and EMT pathways following PDPN silencing in TPC1 and BcPAP thyroid cancer cell lines, i.e. CD44, RhoA, Snail, Twist1, Vimentin, Paxillin and PTK2. We found that PDPN knock-down did not change the expression levels of $\mathrm{E} / \mathrm{R} / \mathrm{M}$ regulators RhoA and $\mathrm{CD} 44$, nor that of Twist1, Vimentin, Paxillin and Snai1, in either of the studied cell lines (Fig. 6). Interestingly, we observed an enhanced expression and phosphorylation of protein tyrosine kinase 2 (PTK2; Fig. 6) which has been shown to play an important role in focal cellular adhesion.

\section{Podoplanin knock-down alters the expression and activity of MMPs in both BCPAP and TPC1 cell lines}

Since the invasion and metastasis of cells expressing PDPN seem to depend on the activity of matrix metalloproteinases, we analyzed the expression and activity of
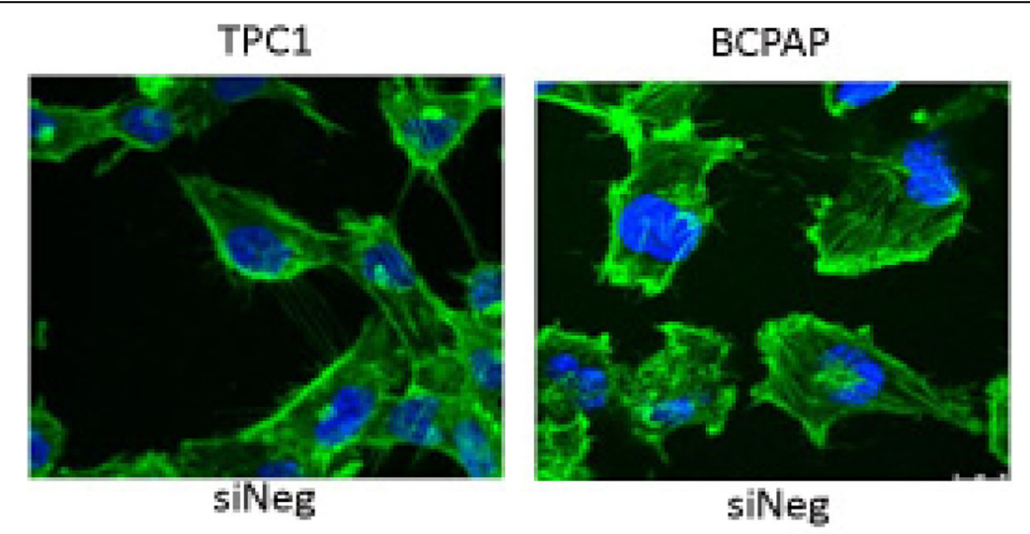

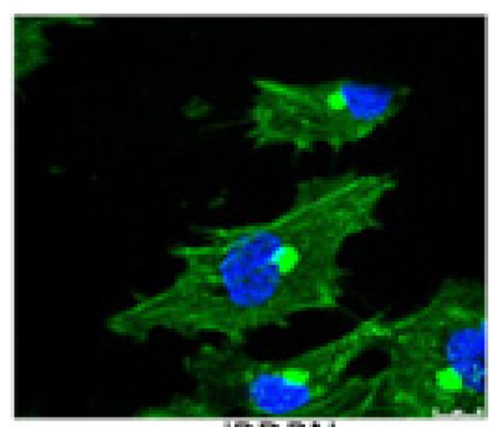

SIPDPN

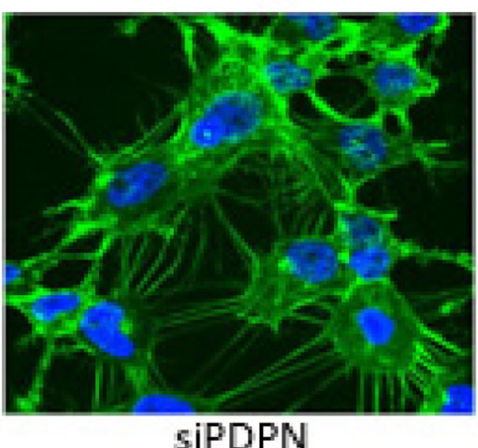

siPDPN

Fig. 5 Silencing of PDPN changes cytoskeleton organization in TPC1 and BCPAP cells. Immunofluorescent staining of cytoskeleton in TPC1 and BCPAP cells transfected with siPDPN or control siNeg. To visualize filamentous actin (F-actin), cells were fixed with with 4\% PFA/PBS, permeabilized with $0.1 \%$ Triton X-100, and stained with Phalloidin-FITC (green), and counterstained with DAPI (blue). Magnification: 630x 

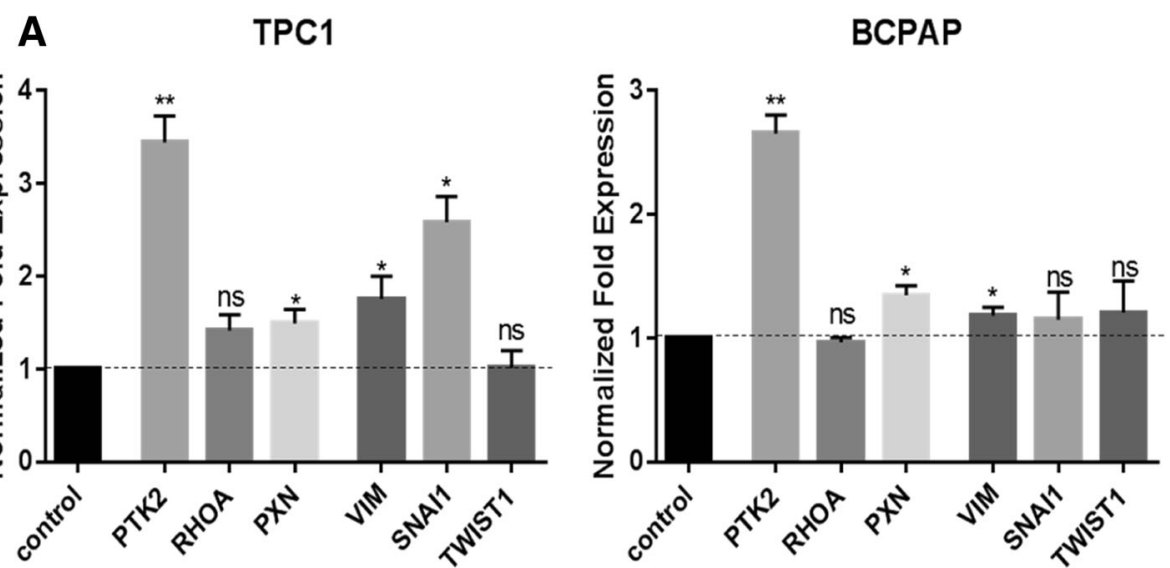

B
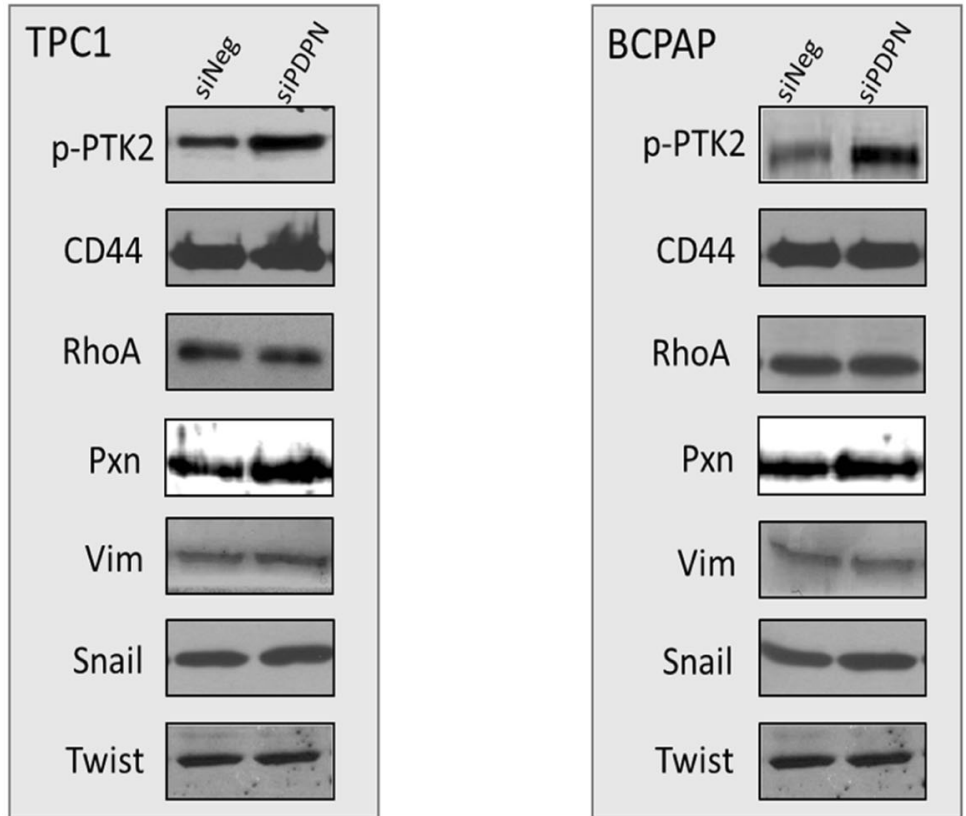

Fig. 6 Podoplanin silencing does not alter the expression of proteins involved in the epithelial-mesenchymal transition (EMT) in thyroid cancer cells. a. RT-qPCR analysis of mRNA levels in TPC1 and BCPAP thyroid cancer cells $48 \mathrm{~h}$ after transfection. The results were normalized to the $18 \mathrm{~S}$ rRNA levels. The bars represent the average fold change in transcripts levels in cells transfected with siPDPN compared to cells transfected with siNeg. Values are means from at least three independent experiments. Data are presented as means \pm standard errors of the mean (SEM) *P $<$ 0.05 ; ${ }^{*} P<0.01$. b. Western blot analysis of CD44, RhoA, Twist, Snail, Vimentin, PTK2 expression levels $48 \mathrm{~h}$ after transfection with siPDPN or control siNeg in TPC1 and BCPAP cells. Total protein were separated by SDS-PAGE, transferred onto a nitrocellulose membrane, and probed with specific antibodies. The results are representatives of three independent experiments

MMP-2 and MMP-9 in PDPN depleted TPC1 and BcPAP cell lines using RT-qPCR, immunofluorescence, and gelatin or collagen zymography. The two cell lines showed distinct profiles of MMP expression after PDPN silencing (Fig. 7a). We found that changes in the MMP expression after PDPN silencing were paralleled by alterations in the activity of MMPs as measured by zymography in both cell lines. Surprisingly, TPC1 and BcPAP cells displayed opposed patterns of MMP-2 and MMP-9 expression and activity before and after PDPN silencing. PDPN knock-down in TPC1 cells led to an increased expression and activity of MMP-2, whereas the expression and activity of MMP-9 were reduced. In contrast, in BcPAP cells, PDPN silencing resulted in an increased MMP-9 expression and activity, and decreased expression and activity of MMP-2 (Fig. 7b-e).

\section{Role of the MAPK signaling pathway}

We hypothesized that one of the possible mechanisms responsible for observed PDPN-dependent phenotype in BcPAP cells, so different from that observed in TPC1, may be a constitutive activation of the BRAF pathway 

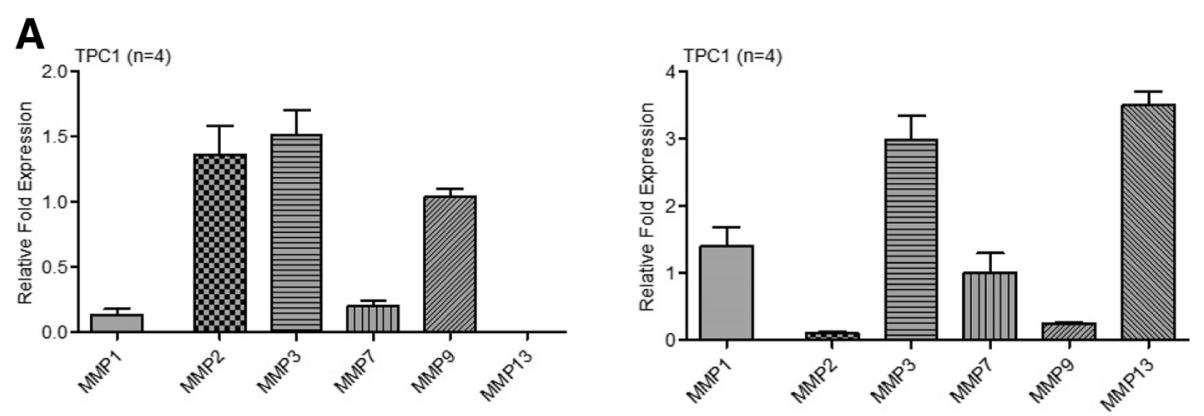

B
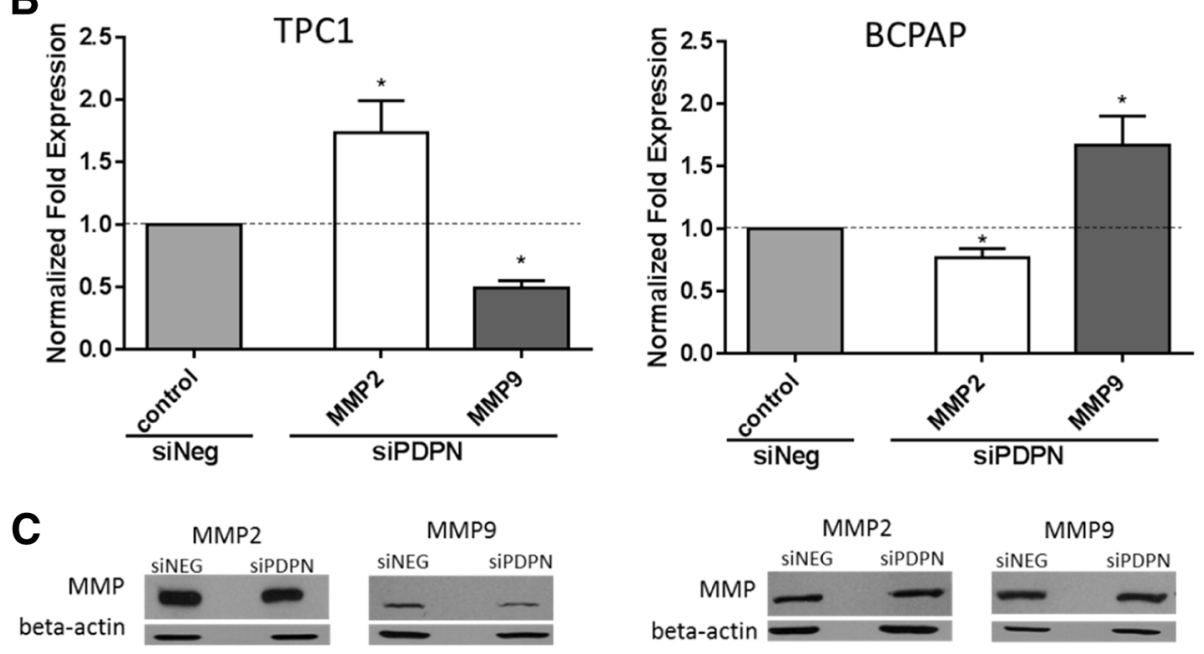

D
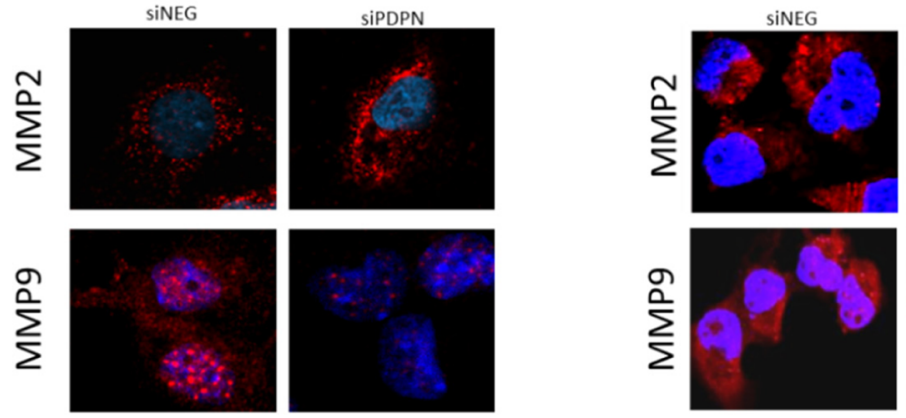

E

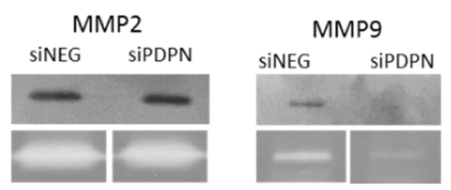

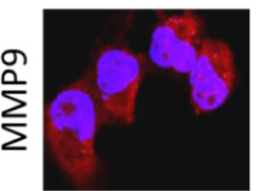

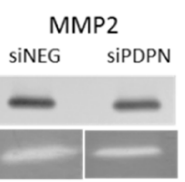

SIPDPN
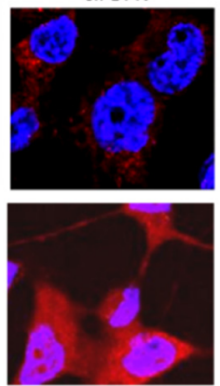

MMP9

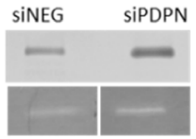

Fig. 7 PDPN silencing alters the expression and activity of matrix metalloproteinases (MMPs) in TPC1 and BcPAP cells. a. The pattern of expression of MMPs mRNA levels in TPC1 and BCPAP cells. b. RT-qPCR analysis of MMP mRNA levels in $48 \mathrm{~h}$ after siPDPN transfection compared to those in non-transfected cells. The results were normalized to $18 \mathrm{~S}$ RNA levels. The bars represent the average fold expression. Data are presented as means \pm standard errors of the mean (SEM) of results from at least three independent experiments ${ }^{*} P<0.05$. c. Western blot analysis of MMP expression levels $48 \mathrm{~h}$ after PDPN silencing. Total protein extracts were separated by SDS-PAGE, transferred onto a nitrocellulose membrane, and probed with specific antibodies. The results are representative of three independent experiments. $\mathbf{d}$. Immunofluorescent staining for MMP-2 and MMP-9 in thyroid cancer cell lines transfected with siPDPN or control siNeg. Cells were fixed with 4\% PFA/PBS, permeabilized with $0.1 \%$ Triton X-100, and stained with an anti-MMP-2 or anti-MMP-9 monoclonal antibody followed by the DyLight549-conjugated secondary antibody (red), and counterstained with DAPI (blue). Confocal microscopy magnification: 630x. e. Gelatin and collagen zymography for TPC1 and BcPAP cell lines after PDPN silencing 

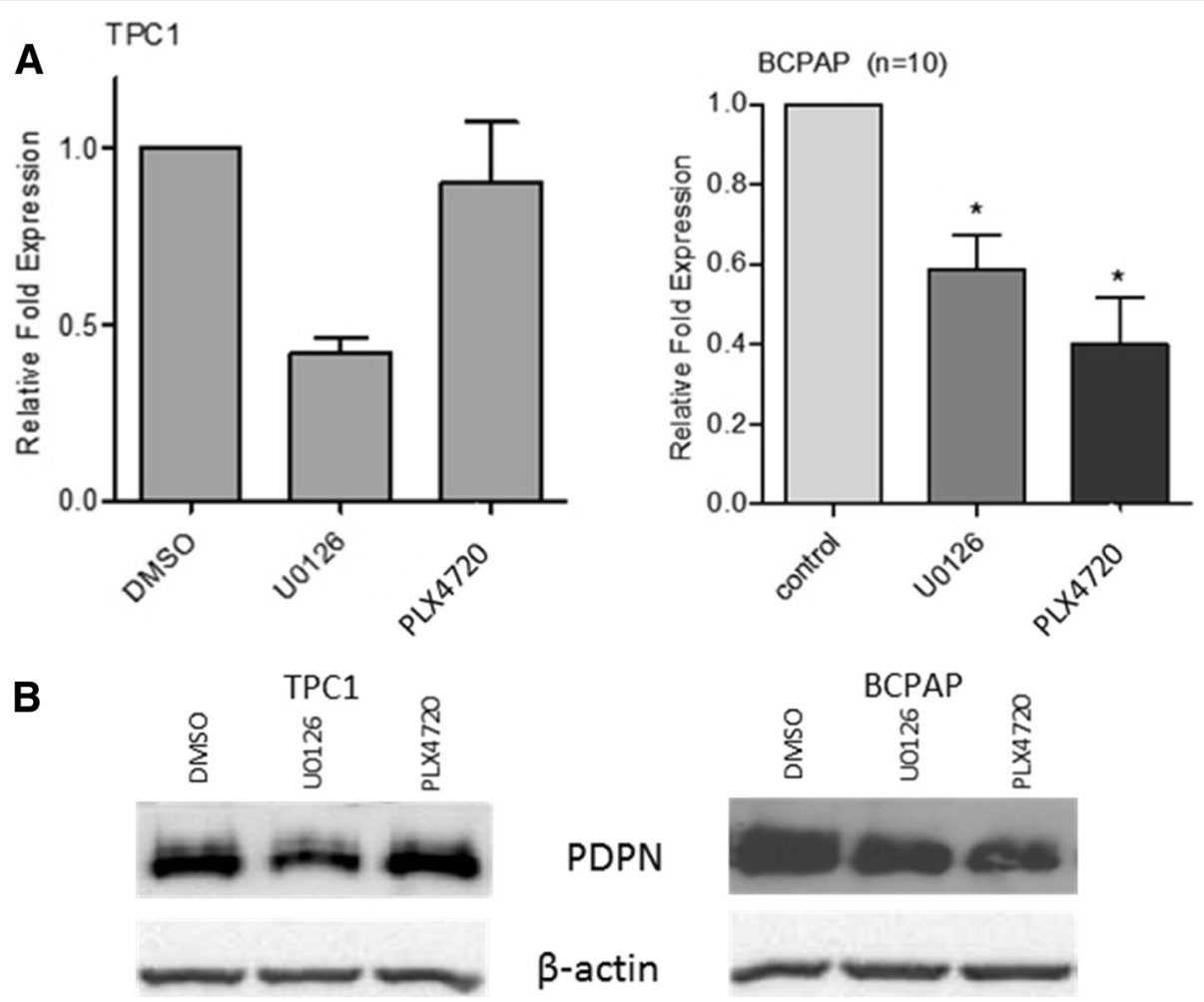

Fig. 8 Effect of MAPK pathway inhibition on PDPN expression in BCPAP and TPC1 cell lines. a. RT-qPCR analysis of PDPN mRNA levels in BCPAP and TPC1 cells $24 \mathrm{~h}$ after treatment with $10 \mu \mathrm{M}$ PLX4720 (BRAF V600E inhibitor), $50 \mu \mathrm{M}$ U0126 (MEK1/2 inhibitor), or DMSO as a negative control. The results were normalized to $18 \mathrm{~S}$ rRNA levels. The bars represent the average fold change in transcript quantity in cells treated with the inhibitors compared to cells treated with DMSO. The results are representative of three independent experiments. Data are presented as the means \pm standard errors of the mean $(\mathrm{SEM}){ }^{*}<\mathrm{P}, 0.05$; ${ }^{*}<\mathrm{P}, 0.01$. b. Western blot analysis of PDPN, phosphorylated ERK and $\beta$-actin protein levels in TPC1 and BCPAP cells $24 \mathrm{~h}$ after treatment with $10 \mu \mathrm{M}$ PLX4720, $50 \mu \mathrm{M} \cup 0126$, or DMSO as negative control

and downstream mitogen-activated protein kinase (MAPK) signaling. To test this hypothesis we inhibited the activity of the BRAF V600E or Mek $1 / 2$ allele using the PLX4720 or U0126 inhibitory compound, respectively. We observed that the inhibition of the MAPK pathway resulted in decreased levels of PDPN expression in both studied thyroid cancer cell lines. Consistently with the specificity of the used inhibitors, the PDPN transcript levels in BcPAP cells decreased by $60 \%$ after treatment with PLX4720 and by $40 \%$ when using UO126 ( $P$-value $<0.05$; Fig. $8 \mathrm{a})$. In TPC1 cells, PDPN mRNA levels decreased by about $50 \%$ only after UO126 treatment ( $P$-value $<0.01$, Fig. $8 \mathrm{a})$. Western blot analyses confirmed an efficient inhibition of the MAPK signaling by U0126 in TPC1 cells and by both U0126 and PLX47020 in BcPAP cells, as well as decreased PDPN expression following the treatment with the two inhibitors in both cell lines (Fig. 8b).

\section{Discussion}

The expression of podoplanin (PDPN) has been found in various human cancers, including differentiated thyroid carcinoma. However, its role in carcinogenesis is still unclear. Many reports have suggested that it has a pro-metastatic activity $[11,18,22,24,41]$. In our previous study, we have shown that it is expressed only in PTC- derived cell lines (TPC1 and BcPAP, with higher expression levels in the latter cell line) and also in a proportion of human PTC tissues. The functional analysis of PDPN in TPC1 cells suggested that it has a pro-metastatic activity also in thyroid cancer, enhancing invasiveness of malignant thyroid cells [19]. To further assess the role of PDPN in the biology of papillary thyroid cancer, in the current study we assessed the effect of PDPN silencing in these two papillary thyroid cancer cell lines in more detail. Of note, these cell lines differ in their genetic background TPC1 harbors the RET/PTC1 rearrangement, and BcPAP cell line carries the BRAF V600E mutation.

We had previously found that PDPN depletion in TPC1 cells significantly suppressed their in vitro motility, migration and invasion capacities, while cell viability, proliferation and apoptosis were not changed [19]. In this study PDPN depletion in these cells also affected anchorage-dependent and independent growth. Surprisingly, in BcPAP cells the PDPN depletion significantly 
increased their capacity to migrate and invade without detectable changes in viability, proliferation and apoptosis or cell cycle arrest. Moreover, reduced levels of PDPN correlated with an increased capacity for anchorage-independent growth and clonogenic outgrowth in these cells. Our results revealed an opposed effect of PDPN expression on malignant features of TPC1 and BcPAP cell lines. These two cell lines have different genetic background, that is either the RET/PTC translocation (TPC1), or BRAF V600E mutation (BCPAP). Therefore, the differences in the PDPN-induced phenotype could be related to the differences in their genetic background but further experiments are needed to test this hypothesis. We also found that modifying PDPN expression in both TPC1 and BcPAP cells did not affect the cell proliferation, apoptosis or cell cycle arrest. This suggests that PDPN activity is rather not dependent on the genetic background determining the regulation of these processes in papillary thyroid cancer cells.

It had been shown before that PDPN directly binds to ezrin and moesin and that its overexpression results in increased phosphorylation of the ezrin/radixin/moesin (E/R/ M) proteins [11, 25]. E/R/M phosphorylation turns the proteins to active conformations that expose the binding sites which connect molecular complexes containing phospholipids, membrane receptors, transmembrane proteins to the actin filaments, thus playing a role in the regulation of the cytoskeleton and various cellular signaling pathways, cells motility and morphology $[42,43]$. Therefore, we have analyzed the expression of the $E / R / M$ mRNA and proteins as well as their phosphorylation status in the two thyroid cancer cell lines transfected with siPDPN and control siNeg. Surprisingly, the levels of phosphor-ERM increased markedly after PDPN depletion in both studied cell lines compared to control cells that had been transfected with siNeg, whereas both E/R/M transcript and protein level were not altered by transfection. Immunofluorescence co-staining of PDPN and phospho-E/R/M corroborated these results in both cell lines (Fig. 4c).

As PDPN was shown to mediate remodeling of the actin cytoskeleton and filopodia-like formation in addition to induction of cell migration [11, 44], we examined filamentous actin distribution and cell morphology of papillary thyroid cancer cells $48 \mathrm{~h}$ after PDPN silencing. We observed that suppressing PDPN expression significantly modified cytoskeleton and resulted in remodeling of cell shape in both TPC1 and BcPAP cells. Moreover, the morphology of cells from the two cell lines markedly differed. In TPC1 cells, PDPN depletion led to impaired cell-spreading with reduced protrusions, while in BcPAP cells PDPN knock-down induced an increase in the number of cellular protrusions. The observed morphological alterations were supported by the results of Western blot analyses which showed that expression levels of active forms of the $E / R / M$ proteins increased with PDPN overexpression in papillary thyroid carcinoma cells. However, these observations do not explain the differences in response to the silencing of PDPN observed between the two cell lines. Therefore, we seeked to elucidate the underlying mechanisms of PDPN impact on the E/R/M and EMT pathways in papillary thyroid cancer by analyzing the main actors of these pathways.

Epithelial to mesenchymal transition (EMT) not only plays an important role during embryonic development but also contributes to pathological processes, such as invasion and metastatic dissemination of cancer cells $[45,46]$. Among a variety of factors that promote EMT, the involvement of PDPN and its cell-type specific function in the EMT process, as well as the role of other regulatory proteins associated and/or activated with the process were also demonstrated in vitro [11, 25, 42] Therefore, we studied the expression of CD44, RhoA, Snail, Twist1, Vimentin, Paxillin and PTK2 proteins involved in the E/R/M or EMT pathway in TPC1 and BcPAP thyroid cell lines knock-down, which suggests that alternative signaling pathways were responsible for the observed changes in the cell motility and morphology. Interestingly, we detected enhanced expression and phosphorylation of protein tyrosine kinase 2 (PTK2; Fig. 6b) which has been shown to play an important role in focal cellular adhesion.

The invasion of tissues by cancer cells depends on the degradation of extracellular matrix (ECM) component and of the basement membrane surrounding the tumor. This complex multifactorial process involves several matrix metalloproteinases, including MMP-2 and MMP-9 that degrade ECM [21, 23, 24]. In our study, MMP-2 and MMP-9 in PDPN depleted TPC1 and BcPAP cells displayed inverse expression and activity patterns. In PDPN depleted TPC1 cells, we found a significant decrease in the MMP-9 transcript and protein expression, and its activity corroborated by immunofluorescence with MMP-2 expression not changed, whereas PDPN depleted BcPAP cells showed a significantly enhanced MMP-9 expression on both transcript and protein levels, confirmed by immunofluorescence and zymography. Parental TPC1 and BcPAP cells differ in the expression of MMP-2 and MMP-9, with BcPAP displaying very low expression of both MMPs analyzed, hence the differences in MMP-2 and MMP-9 expression following PDPN silencing in the two cell lines suggest that they may play a role in cancer progression, with different MMPs being involved, depending on the type of cells.

These results are in accordance with those previously reported by others. Studies on the PDPN function in 
cultured cancer cells, in mouse cancer models and in human cancer biopsies have indicated that PDPN promotes cells invasion in vitro and in vivo. Moreover, cellular invasion was totally abrogated after treatment of cultured cells with TIMP2, a natural inhibitor of MMPs [11]. Therefore, it seems that the invasive properties of PDPN-expressing cells depend on the activity of MMPs [11]. It was also shown that PDPN colocalizes with MMP-9 in the lymphatic endothelial cells [47]. The results of several studies have shown that PDPN is involved in ECM remodeling, and that the process of ECM degradation predominantly involves MMP-2 and MMP-9 whose expression correlates with prognosis in some cancer types [24, 47-52].

The characterstic genetic alterations harbored by the TPC1 and BCPAP activate the MAPK signaling pathway. To check whether there is an association between PDPN expression and the MAPK pathway activity, we inhibited components of the MAPK pathway: BRAFV600E and MEK1/2, in PDPN depleted cells. Interestingly, the inhibition of the MAPK pathway did not only decrease PDPN expression, but also increased phosphorylation of the $\mathrm{E} / \mathrm{R} / \mathrm{M}$ proteins and reduced cell migration in TPC1 cells, while in BcPAP cells, the inhibition of both BRAFV600E and MEK1/2 reduced cell motility. One of the possible mechanisms responsible for the observed PDPN phenotype in BcPAP cells, entirely different from that in the TPC1 cells, may be a constitutive activation of the BRAF pathway and downstream MAPK signaling. To test this hypothesis, we inhibited BRAFV600E and MEK1/2 separately. Our results showed that PDPN expression was associated with the MAPK signaling pathway since inhibited the mutated BRAF and the MEK1/2 kinase led to a reduction in PDPN protein expression. This is consistent with previous studies which had shown that the MAPK pathway was activated as a consequence of the BRAF V600E mutation, the mutant BRAF having a 500 -fold greater kinase activity in vitro than the wild-type protein [53]. Consistently, PLX4720 effectively inhibited PDPN expression only in BcPAP cells, which carry mutated $B R A F$, and not in TPC1 cells.

Cell migration and invasion requires coordination between cytoskeletal reorganization, cell adhesion, interaction with ECM, and proteinase activity for ECM degradation. Our findings in thyroid cancer cells show that PDPN-induced changes of the tumor microenvironment promoted thyroid tumor cell motility, invasion, and metastasis. However, the role of PDPN was strongly dependent on the genetic background of the cells, and regulation of the MAPK pathway through $E / R / M$ and MMPs activity is one of the possible mechanisms involved in these processes. PDPN may facilitate and increase the thyroid cell migration and invasion also by promoting cytoskeleton remodeling, which contributes to increased motility and invasion, and the association between PDPN expression and actin cytoskeleton seems to be mediated by the $\mathrm{E} / \mathrm{R} / \mathrm{M}$ proteins.

\section{Conclusions}

We demonstrated that PDPN knock-down may promote or suppress metastatic potential of cells, depending on their genetic background. Moreover, our data suggest that PDPN pro-oncogenic function is correlated with the expression of $\mathrm{E} / \mathrm{R} / \mathrm{M}$ proteins and metalloproteinase (MMP) activity. We conclude that PDPN may play an important role in the regulation of invasion and migration of papillary thyroid carcinoma cells by activating E/ $\mathrm{R} / \mathrm{M}, \mathrm{MMPs}$ and may also depend on MAPK kinase signaling. Further studies are needed to fully elucidate complex mechanisms underlying essential differences between papillary thyroid cancer cells with different genetic backgrounds and the role of podoplanin in acquiring metastatic potential.

\section{Additional file}

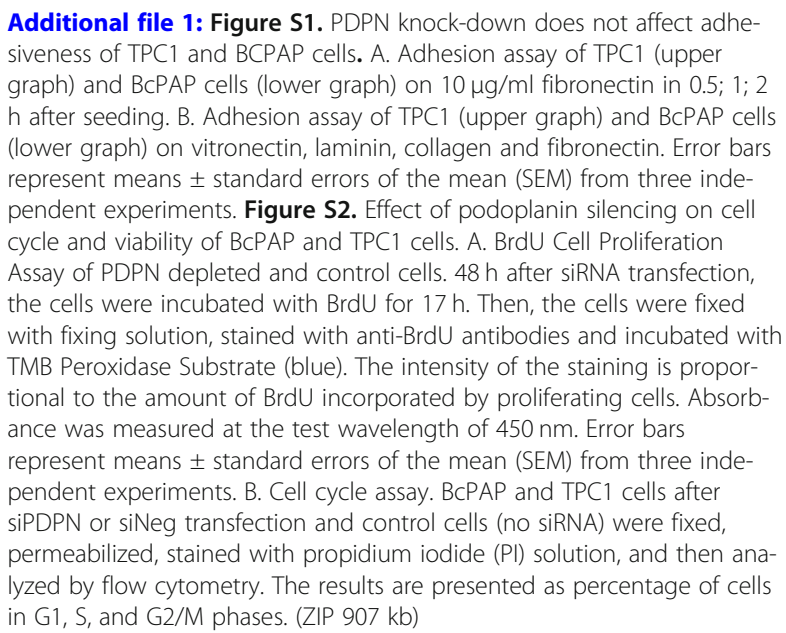

\section{Abbreviations}

BCPAP: Papillary thyroid carcinoma; BRAF: B-type Raf kinase; CD44: Cluster of differentiation 44; DMSO: Dimethyl sulfoxide; ERK: Extracellular-signal regulated kinase; RT-qPCR: quantitative real-time reverse transcription - polymerase chain reaction; MAPK: Mitogen activated protein kinase;

MEK: Mitogen-activated protein kinase; MMPs: Matrix metalloproteinases; PTC: Papillary thyroid cancer; RET: Rearranged during transfection; RhoA: Ras homolog family member $A$; siRNA: Small interfering RNA

\section{Acknowledgements}

Not applicable.

Ethical approval and consent to participate Not applicable.

\section{Funding}

This work was supported by a grant (ref. 2012/07/B/NZ5/02444) from The National Science Center, Poland. The funders had no role in the study design, data collection and analysis, decision to publish, or preparation of the manuscript. 


\section{Availability of data and materials}

The datasets used and/or analyzed in this study may be received from the corresponding author on reasonable request.

\section{Authors' contributions}

$\mathrm{BC}$ was the principal investigator; $\mathrm{BC}, \mathrm{DG}$, and JS were involved in elaborating research hypotheses, in the study design, and the interpretation of data; JS, DG and MR performed the experiments; HD carried out the Western blot analysis and immunohistochemistry; DG performed statistical and graphical analyses; JS and BC wrote the manuscript. All the authors read and approved the final manuscript.

\section{Consent for publication}

Not applicable.

\section{Competing interests}

The authors declare that they have no competing interests.

\section{Publisher's Note}

Springer Nature remains neutral with regard to jurisdictional claims in published maps and institutional affiliations.

\section{Received: 29 September 2017 Accepted: 20 December 2018}

\section{Published online: 17 January 2019}

\section{References}

1. Zimmer G, Oeffner F, von Messling V, Tschernig T, Grone HJ, Klenk HD, Herrler G. Cloning and characterization of gp36, a human mucin-type glycoprotein preferentially expressed in vascular endothelium. Biochem J. 1999:341:277-84.

2. Boucherot A, Schreiber R, Pavenstadt H, Kunzelmann K. Cloning and expression of the mouse glomerular podoplanin homologue gp38P Nephrol Dial Transplant. 2002;17:978-84

3. Suzuki-Inoue K, Kato Y, Inoue O, Kaneko MK, Mishima K, Yatomi Y, Yamazaki Y, Narimatsu H, Ozaki Y. Involvement of the snake toxin receptor CLEC-2, in podoplanin-mediated platelet activation, by cancer cells. J Biol Chem. 2007; 282:25993-6001.

4. BreitenederGeleff S, Matsui K, Soleiman A, Meraner P, Poczewski H, Kalt R, Schaffner G, Kerjaschki D. Podoplanin, novel 43-kd membrane protein of glomerular epithelial cells, is down-regulated in puromycin nephrosis. Am J Pathol. 1997;151:1141-52.

5. Martin-Villar E, Scholl FG, Gamallo C, Yurrita MM, Munoz-Guerra M, Cruces J, Quintanilla M. Characterization of human PA2.26 antigen (T1 alpha-2, podoplanin), a small membrane mucin induced in oral squamous cell carcinomas. Int J Cancer. 2005;113:899-910.

6. Schacht V, Dadras SS, Johnson LA, Jackson DG, Hong YK, Detmar M. Upregulation of the lymphatic marker podoplanin, a mucin-type transmembrane glycoprotein, in human squamous cell carcinomas and germ cell tumors. Am J Pathol. 2005;166:913-21.

7. Ordonez NG. Podoplanin: A novel diagnostic immunohistochemical marker. Adv Anat Pathol. 2006;13:83-8.

8. Breiteneder-Geleff $\mathrm{S}$, Soleiman A, Kowalski H, Horvat R, Amann G, Kriehuber E, Diem K, Weninger W, Tschachler E, Alitalo K, Kerjaschki D. Angiosarcomas express mixed endothelial phenotypes of blood and lymphatic capillaries Podoplanin as a specific marker for lymphatic endothelium. Am J Pathol. 1999:154:385-94.

9. Kato Y, Fujita N, Kunita A, Sato S, Kaneko M, Osawa M, Tsuruo T. Molecular identification of Aggrus/T1 alpha as a platelet aggregation-inducing factor expressed in colorectal tumors. J Biol Chem. 2003;278:51599-605.

10. Kato Y, Kaneko M, Sata M, Fujita N, Tsuruo T, Osawa M. Enhanced expression of Aggrus (T1alpha/podoplanin), a platelet-aggregation-inducing factor in lung squamous cell carcinoma. Tumor Biol. 2005;26:195-200.

11. Wicki A, Lehembre F, Wick N, Hantusch B, Kerjaschki D, Christofori G. Tumor invasion in the absence of epithelial-mesenchymal transition: Podoplaninmediated remodeling of the actin cytoskeleton. Cancer Cell. 2006;9:261-72.

12. Kimura N, Kimura I. Podoplanin as a marker for mesothelioma. Pathol Int. 2005;55:83-6.

13. Kato Y, Sasagawa I, Kaneko M, Osawa M, Fujita N, Tsuruo T. Aggrus: a diagnostic marker that distinguishes seminoma from embryonal carcinoma in testicular germ cell tumors. Oncogene. 2004;23:8552-6.
14. Mishima K, Kato Y, Kaneko MK, Nakazawa Y, Kunita A, Fujita N, Tsuruo T, Nishikawa R, Hirose T, Matsutani M. Podoplanin expression in primary central nervous system germ cell tumors: a useful histological marker for the diagnosis of germinoma. Acta Neuropathol. 2006;111:563-8.

15. Mishima K, Kato Y, Kaneko MK, Nishikawa R, Hirose T, Matsutani M. Increased expression of podoplanin in malignant astrocytic tumors as a novel molecular marker of malignant progression. Acta Neuropathol. 2006; 111:483-8.

16. Kato Y, Kaneko MK, Kuno A, Uchiyama N, Amano K, Chiba Y, Hasegawa Y, Hirabayashi J, Narimatsu H, Mishima K, Osawa M. Inhibition of tumor cellinduced platelet aggregation using a novel anti-podoplanin antibody reacting with its platelet-aggregation-stimulating domain. Biochem Biophys Res Commun. 2006:349:1301-7.

17. Suurmeijer AJH, Fletcher CDM. Papillary haemangioma. A distinctive cutaneous haemangioma of the head and neck area containing eosinophilic hyaline globules. Histopathology. 2007;51:638-48.

18. Hansen T, Katenkamp K, Bittinger F, Kirkpatrick CJ, Katenkamp D. D2-40 labeling in lymphangiomyoma/lymphangiomyomatosis of the soft tissue: further evidence of lymphangiogenic tumor histogenesis. Virchows Arch. 2007;450:449-53.

19. Rudzinska M, Gawel D, Sikorska J, Karpinska KM, Kiedrowski M, Stepien T, Marchlewska M, Czarnocka B. The role of Podoplanin in the biology of differentiated thyroid cancers. PLoS One. 2014;9:12.

20. Uhrin P, Zaujec J, Breuss JM, Olcaydu D, Chrenek P, Stockinger $H$, Fuertbauer E, Moser M, Haiko P, Fassler R, et al. Novel function for blood platelets and podoplanin in developmental separation of blood and lymphatic circulation. Blood. 2010;115:3997-4005.

21. Wicki A, Christofori G. The potential role of podoplanin in tumour invasion. Br J Cancer. 2007:96:1-5.

22. Kreppel M, Scheer M, Drebber U, Ritter L, Zoeller JE. Impact of podoplanin expression in oral squamous cell carcinoma: clinical and histopathologic correlations. Virchows Arch. 2010:456:473-82.

23. Tokuraku M, Sato H, Murakami S, Okada Y, Watanabe Y, Seiki M. Activation of the precursor of gelatinase a/72 KDA type-iv collagenase/MMP-2 in lung carcinomas correlates with the express ion of membrane-type matrix METALLO proteinase (MT-MMP) and with LYMPH-node metastasis. Int J Cancer. 1995;64:355-9.

24. Inoue $H$, Miyazaki $Y$, Kikuchi $K$, Yoshida N, Ide F, Ohmori $Y$, Tomomura A Sakashita H, Kusama K. Podoplanin promotes cell migration via the EGF-SrcCas pathway in oral squamous cell carcinoma cell lines. J Oral Sci. 2012;54: 241-50.

25. Martin-Villar E, Megias D, Castel S, Yurrita MM, Vilaro S, Quintanilla M. Podoplanin binds ERM proteins to activate RhoA and promote epithelialmesenchymal transition. J Cell Sci. 2006;119:4541-53.

26. Cueni LN, Hegyi I, Shin JW, Albinger-Hegyi A, Gruber S, Kunstfeld R, Moch H Detmar M. Tumor Lymphangiogenesis and metastasis to Lymph nodes induced by Cancer cell expression of Podoplanin. Am J Pathol. 2010;177:1004-16.

27. Martin-Villar E, Fernandez-Munoz B, Parsons M, Yurrita MM, Megias D, PerezGomez E, Jones GE, Quintanilla M. Podoplanin associates with CD44 to promote directional cell migration. Mol Biol Cell. 2010;21:4387-99.

28. Scholl FG, Gamallo C, Vilaro S, Quintanilla M. Identification of PA2.26 antigen as a novel cell-surface mucin-type glycoprotein that induces plasma membrane extensions and increased motility in keratinocytes. J Cell Sci. 1999;112:4601-13.

29. Thiery JP, Acloque H, Huang RY, Nieto MA. Epithelial-mesenchymal transitions in development and disease. Cell. 2009;139:871-90.

30. Fernandez-Munoz B, Yurrita MM, Martin-Villar E, Carrasco-Ramirez P, Megias $D$, Renart J, Quintanilla M. The transmembrane domain of podoplanin is required for its association with lipid rafts and the induction of epithelialmesenchymal transition. Int J Biochem Cell Biol. 2011;43:886-96.

31. Renart J, Carrasco-Ramirez P, Fernandez-Munoz B, Martin-Villar E, Montero L, Yurrita MM, Quintanilla M. New insights into the role of podoplanin in epithelial-mesenchymal transition. Int Rev Cell Mol Biol. 2015;317:185-239.

32. Kimura ET, Nikiforova MN, Zhu ZW, Knauf JA, Nikiforov YE, Fagin JA. High prevalence of BRAF mutations in thyroid cancer: genetic evidence for constitutive activation of the RET/PTC-RAS-BRAF signaling pathway in papillary thyroid carcinoma. Cancer Res. 2003;63:1454-7.

33. Soares P, Trovisco V, Rocha AS, Lima J, Castro P, Preto A, Maximo V, Botelho T, Seruca R, Sobrinho-Simoes M. BRAF mutations and RET/PTC rearrangements are alternative events in the etiopathogenesis of PTC. Oncogene. 2003;22:4578-80. 
34. Rowe LR, Bentz BG, Bentz JS. Detection of BRAF V600E activating mutation in papillary thyroid carcinoma using PCR with allele-specific fluorescent probe melting curve analysis. J Clin Pathol. 2007;60:1211-5.

35. Xing M. Molecular pathogenesis and mechanisms of thyroid cancer. Nat Rev Cancer. 2013;13:184-99.

36. Maruyama Y, Maruyama K, Kato Y, Kajiya K, Moritoh S, Yamamoto K, Matsumoto Y, Sawane M, Kerjaschki D, Nakazawa T, Kinoshita S. The effect of Podoplanin inhibition on Lymphangiogenesis under pathological conditions. Invest Ophthalmol Vis Sci. 2014;55:4813-22.

37. Knauf JA, Kuroda H, Basu S, Fagin JA. RET/PTC-induced dedifferentiation of thyroid cells is mediated through Y1062 signaling through SHC-RAS-MAP kinase. Oncogene. 2003;22:4406-12.

38. Mesa C Jr, Mirza M, Mitsutake N, Sartor M, Medvedovic M, Tomlinson C, Knauf JA, Weber GF, Fagin JA. Conditional activation of RET/PTC3 and BRAFV600E in thyroid cells is associated with gene expression profiles that predict a preferential role of BRAF in extracellular matrix remodeling. Cancer Res. 2006;66:6521-9.

39. Giordano TJ, Kuick R, Thomas DG, Misek DE, Vinco M, Sanders D, Zhu ZW, Ciampi R, Roh M, Shedden K, et al. Molecular classification of papillary thyroid carcinoma: distinct BRAF, RAS, and RET/PTC mutation-specific gene expression profiles discovered by DNA microarray analysis. Oncogene. 2005; 24:6646-56.

40. Tanaka J, Ogura T, Sato H, Hatano M. Establishment and biological characterization of an in vitro human cytomegalovirus latency model. Virology. 1987;161:62-72.

41. Valster A, Tran NL, Nakada M, Berens ME, Chan AY, Symons M. Cell migration and invasion assays. Methods. 2005;37:208-15.

42. Suzuki H, Onimaru M, Yonemitsu Y, Maehara Y, Nakamura S, Sueishi K. Podoplanin in cancer cells is experimentally able to attenuate prolymphangiogenic and lymphogenous metastatic potentials of lung squamoid cancer cells. Mol Cancer. 2010;9.

43. Zhu L, Zhou R, Mettler S, Wu T, Abbas A, Delaney J, Forte JG. High turnover of ezrin T567 phosphorylation: conformation, activity, and cellular function. Am J Physiol Cell Physiol. 2007;293:C874-84.

44. Grau SJ, Trillsch F, Tonn JC, Goldbrunner RH, Noessner E, Nelson PJ, von Luettichau I. Podoplanin increases migration and angiogenesis in malignant glioma. Int J Clin Exp Pathol. 2015;8:8663-70.

45. Fehon RG, McClatchey Al, Bretscher A. Organizing the cell cortex: the role of ERM proteins. Nat Rev Mol Cell Biol. 2010;11:276-87.

46. Thiery JP. Epithelial-mesenchymal transitions in tumour progression. Nat Rev Cancer. 2002;2:442-54

47. Gotzmann J, Mario M, Eger A, Schulte-Hermann R, Foisner R, Beug H, Mikulits W. Molecular aspects of epithelial cell plasticity: implications for local tumor invasion and metastasis. Mutat Res. 2004;566:9-20.

48. Yang S, Zhu X, Cai L, Cheng H, Zhao R, Wang H, Zhao H, Wang Z. Role of tumor-associated lymphatic endothelial cells in metastasis: a study of epithelial ovarian tumor in vitro. Cancer Sci. 2010;101:679-85.

49. Tsuneki M, Maruyama S, Yamazaki M, Cheng J, Saku T. Podoplanin expression profiles characteristic of odontogenic tumor-specific tissue architectures. Pathol Res Pract. 2012;208:140-6.

50. Lin C-Y, Tsai P-H, Kandaswami CC, Lee P-P, Huang C-J, Hwang J-J, Lee M-T. Matrix metalloproteinase-9 cooperates with transcription factor snail to induce epithelial-mesenchymal transition. Cancer Sci. 2011;102:815-27.

51. Thomas GT, Lewis MP, Speight PM. Matrix metalloproteinases and oral cancer. Oral Oncol. 1999;35:227-33.

52. Kurahara S, Shinohara M, Ikebe T, Nakamura S, Beppu M, Hiraki A, Takeuch $\mathrm{H}$, Shirasuna K. Expression of MMPs, MT-MMP, and TIMPs in squamous cell carcinoma of the oral cavity: correlations with tumor invasion and metastasis. Head Neck. 1999;21:627-38.

53. Wan PTC, Garnett MJ, Roe SM, Lee S, Niculescu-Duvaz D, Good VM, Jones CM, Marshall CJ, Springer CJ, Barford D, et al. Mechanism of activation of the RAF-ERK signaling pathway by oncogenic mutations of B-RAF. Cell. 2004;116:855-67.

\section{Ready to submit your research? Choose BMC and benefit from:}

- fast, convenient online submission

- thorough peer review by experienced researchers in your field

- rapid publication on acceptance

- support for research data, including large and complex data types

- gold Open Access which fosters wider collaboration and increased citations

- maximum visibility for your research: over $100 \mathrm{M}$ website views per year

At $\mathrm{BMC}$, research is always in progress.

Learn more biomedcentral.com/submissions 